\title{
NODULAÇÃO E ABSORÇÃO DE NITROGÊNIO PELO AMENDOIM EM RESPOSTA À CALAGEM, COBALTO E MOLIBDÊNIO
}

\author{
Eduardo Fávero Caires ${ }^{1,3 *}$; Ciro Antonio Rosolem²,3 \\ ${ }^{1}$ Depto. de Ciência do Solo e Engenharia Agrícola - UEPG, CEP: 84010-790 - Ponta Grossa, PR. \\ ${ }_{3}^{2}$ Depto. de Agricultura e Melhoramento Vegetal - FCA/UNESP, C.P. 237 - CEP: 18608-901-Botucatu, SP. \\ ${ }^{3}$ Bolsista CNPq. \\ *Autor correspondente <efcaires@uepg.br>
}

\begin{abstract}
RESUMO: A resposta do amendoim à calagem tem sido atribuída ao fornecimento de cálcio, mas também tem sido observada maior absorção de nitrogênio. Um experimento foi desenvolvido em casa de vegetação, em vasos de polietileno, utilizando-se um Latossolo Vermelho distrófico textura média, para estudar os efeitos da calagem e da aplicação de cobalto e molibdênio sobre a nodulação e a absorção de nitrogênio pelo amendoim, cultivar Tatu. O delineamento experimental empregado foi o de blocos ao acaso, em esquema fatorial 4x3, com quatro repetições. Os tratamentos do fatorial constituíram-se de quatro aplicações de nutrientes nas sementes (sem aplicação; $0,16 \mathrm{~g} \mathrm{~kg}^{-1}$ de Co; 0,58 $\mathrm{g} \mathrm{kg}^{-1}$ de Mo e 0,16 + 0,58 g kg-1 de Co e Mo, respectivamente) e três doses de calcário $\left(0,4\right.$ e $\left.6 \mathrm{t} \mathrm{ha}^{-1}\right)$. A aplicação de cobalto nas sementes não exerceu efeito sobre a nodulação e a absorção de nitrogênio pelo amendoim. A calagem aumentou a absorção de nitrogênio pelo amendoim, provavelmente por causar melhoria na fixação simbiótica do $\mathrm{N}_{2}$, em decorrência da formação de maior número de nódulos. Apesar do molibdênio ter aumentado a matéria seca de nódulos na planta de amendoim, a sua aplicação não influenciou a absorção de nitrogênio, mostrando que a redução da toxicidade de manganês pela calagem foi mais importante do que o aumento da disponibilidade de molibdênio para a formação de nódulos e a fixação simbiótica do $\mathrm{N}_{2}$.
\end{abstract}

Palavras-chave: Arachis hypogaea, fixação simbiótica, manganês

\section{NODULATION AND NITROGEN UPTAKE BY PEANUT AS AFFECTED BY LIME, COBALT, AND MOLYBDENUM}

\begin{abstract}
The response of the peanut plant to lime has been associated with calcium nutrition, but a higher nitrogen uptake has been observed in limed plots. A greenhouse experiment was conducted using a Red Latosol (Rhodic Hapludox) to study the effects of molybdenum, cobalt and liming on the nodulation and $\mathrm{N}$ uptake by peanut. A randomized block design was used, with four replicaties, in a factorial $4 \times 3$ scheme. Seed treatments $\left(0.16 \mathrm{~g} \mathrm{~kg}^{-1}\right.$ of $\mathrm{Co}, 0.58 \mathrm{~g} \mathrm{~kg}^{-1}$ of Mo, $0.16 \mathrm{~g} \mathrm{~kg}^{-1}$ of $\mathrm{Co}_{0}+0.58 \mathrm{~g} \mathrm{~kg}^{-1}$ of Mo and no treatment) were applied to the peanut, cv. "Tatu", grown receiving three rates of lime $\left(0,4\right.$ and $\left.6 \mathrm{t} \mathrm{ha}^{-1}\right)$. There was no effect of seed treatment with $\mathrm{Co}$ on the nodulation and $\mathrm{N}$ uptake of peanut. Liming increased $\mathrm{N}$ uptake due to the formation of a larger number of nodules in the plant. The dry matter of peanut nodules was increased by Mo, but $\mathrm{N}$ uptake was not affected, showing that the decrease in Mn toxicity due to liming was more important than the increase in Mo availability for nodule formation and symbiotic $\mathrm{N}_{2}$ fixation.
\end{abstract}

Key words: Arachis hypogaea, symbiotic fixation, manganese

\section{INTRODUÇÃO}

A resposta do amendoim à calagem tem sido atribuída ao aumento da disponibilidade de cálcio no solo (Walker, 1975; Quaggio et al., 1982) e da absorção de nitrogênio pelas plantas (Rosolem \& Caires, 1998).

A importância do cálcio na nutrição mineral do amendoim tem sido ressaltada na literatura. Sua deficiência provoca vagens chochas e cascas frágeis, diminuindo o índice de fertilidade das flores, reduz o número de ginóforos e torna limitante o crescimento de raízes (Colwell \& Brady, 1945; Walker et al., 1981).

O aumento da absorção de nitrogênio pode ser conseqüência de maior mineralização de nitrogênio orgânico do solo em função da elevação do pH (Rosolem et al., 1990), de melhor distribuição do sistema radicular devido à correção do subsolo ácido (Caires \& Rosolem,
1991) ou de maior eficiência da fixação simbiótica do $\mathrm{N}_{2}$ em decorrência da menor acidez do solo (Blamey \& Chapman, 1982).

$\mathrm{O}$ amendoim depende da fixação simbiótica do $\mathrm{N}_{2}$ para sua nutrição, tendo em vista que fertilizantes nitrogenados normalmente não são aplicados. Em solos ácidos e com baixos teores de cálcio, a baixa disponibilidade de molibdênio e a toxicidade de manganês podem prejudicar a absorção de nitrogênio e reduzir a produção de amendoim (Rosolem \& Caires, 1998). Maior eficiência da fixação simbiótica do $\mathrm{N}_{2}$ pelo amendoim tem ocorrido com a aplicação de calcário (Blamey, 1983), de cobalto (Raj, 1987) ou de molibdênio (Hafner et al., 1992). $\mathrm{O}$ aumento na produção de amendoim tem se relacionado com o aumento da concentração de clorofila nas folhas devido à maior absorção de nitrogênio (Caires \& Rosolem, 1999), com a redução do efeito tóxico do manganês sobre 
o processo de fixação simbiótica do $\mathrm{N}_{2}$, através da elevação da relação Ca/Mn nas folhas (Rosolem \& Caires, 1998) e também com a melhoria da nodulação das plantas em decorrência da redução do alumínio tóxico do solo (Blamey \& Chapman, 1982).

O presente trabalho foi realizado com o objetivo de avaliar os efeitos da calagem e da aplicação de cobalto e molibdênio nas sementes sobre a nodulação do amendoim e sua influência na absorção de nitrogênio.

\section{MATERIAL E MÉTODOS}

O experimento foi instalado em casa de vegetação do Departamento de Agricultura e Melhoramento Vegetal da Faculdade de Ciências Agronômicas - UNESP, no município de Botucatu (SP), em vasos de polietileno com capacidade de 5 litros, em 1992. O solo utilizado foi coletado da camada arável de em um Latossolo Vermelho distrófico textura média e passado em peneira de malha de $4 \mathrm{~mm}$. Foi feita uma adubação à base de $110 \mathrm{mg} \mathrm{kg}^{-1}$ de $P$, como superfosfato simples, e de $80 \mathrm{mg} \mathrm{kg}^{-1}$ de $\mathrm{K}$, como cloreto de potássio, misturados com o solo dos vasos.

$O$ delineamento experimental empregado foi o de blocos ao acaso, em esquema fatorial $4 \times 3$, com quatro repetições. Os tratamentos consistiram de quatro aplicações de nutrientes nas sementes: sementes não tratadas, tratadas com cobalto $\left(0,16 \mathrm{~g} \mathrm{~kg}^{-1}\right.$ de Co), com molibdênio $\left(0,58 \mathrm{~g} \mathrm{~kg}^{-1}\right.$ de Mo) e com cobalto mais molibdênio $\left(0,16 \mathrm{~g} \mathrm{~kg}^{-1}\right.$ de $\mathrm{Co}+0,58 \mathrm{~g} \mathrm{~kg}^{-1}$ de Mo), e três doses de calcário dolomítico calcinado, com 95\% de PRNT: 0, 4 e $6 \mathrm{t} \mathrm{ha}^{-1}$. As fontes de cobalto e molibdênio foram sulfato de cobalto $\left(\mathrm{CoSO}_{4} \cdot 7 \mathrm{H}_{2} \mathrm{O}\right)$ e molibdato de amônio $\left[\left(\mathrm{NH}_{4}\right)_{6} \mathrm{Mo}_{7} \mathrm{O}_{24} \cdot 4 \mathrm{H}_{2} \mathrm{O}\right]$. Como o solo foi coletado de parcelas que haviam recebido esses tratamentos de calagem no campo, após 20 meses, visando a elevação da saturação por bases a $50 \%$ e $70 \%$, o calcário não foi novamente aplicado nos vasos. Maiores detalhes sobre 0 solo utilizado podem ser vistos no trabalho de Caires \& Rosolem (1998).

A semeadura do amendoim, cultivar Tatu, foi realizada utilizando-se seis sementes por vaso. O início da emergência das plântulas ocorreu 5 dias após a semeadura. Cerca de 10 dias após foi realizado desbaste, deixando-se duas plantas por vaso. A umidade do solo foi mantida próxima a $80 \%$ da capacidade de retenção de água do solo, por meio de pesagens e regas diárias.

Decorridos 74 dias da emergência, as plantas foram colhidas. A parte aérea foi cortada e o solo foi lavado em água corrente, tomando-se o máximo cuidado para retirar o sistema radicular intacto. Os nódulos presentes no sistema radicular foram destacados e contados. A seguir, os nódulos, as raízes e a parte aérea das plantas foram colocados para secar em estufa com circulação forçada de ar a $60^{\circ} \mathrm{C}$, até atingir massa constante, para determinação da matéria seca. A parte aérea foi moída e determinados os teores de nitrogênio, cálcio e manganês, de acordo com os métodos descritos por Malavolta et al. (1997).
Por ocasião da colheita, foram tomadas amostras de solo dos tratamentos de calagem e determinados o pH em $\mathrm{CaCl}_{2} 0,01 \mathrm{~mol} \mathrm{~L}^{-1}, \mathrm{H}^{+}+\mathrm{Al}{ }^{3+}$ e cátions trocáveis, seguindo os métodos propostos por Raij \& Quaggio (1983).

Os resultados foram submetidos às análises de variância e de regressão. Quando não houve influência significativa da interação calcário $\mathrm{x}$ tratamento de sementes, os efeitos da calagem e do tratamento de sementes com cobalto e, ou molibdênio foram avaliados e discutidos separadamente. Foram ajustadas equações aos dados obtidos em função das doses de calcário, adotando-se como critério para escolha do modelo matemático a magnitude dos coeficientes de determinação significativos ao nível de $5 \%$. Para os tratamentos de sementes, as médias foram comparadas pelo teste de Tukey ao nível de $5 \%$ de probabilidade.

\section{RESULTADOS E DISCUSSÃO}

Os resultados de análises químicas de amostras de solo coletadas 74 dias após a emergência (TABELA 1) mostraram efeito significativo da calagem no aumento dos valores de $\mathrm{pH}$ em $\mathrm{CaCl}_{2}$ 0,01 $\mathrm{mol} \mathrm{L}^{-1}$ e de saturação por bases, bem como nos teores de cálcio e magnésio trocáveis do solo. As plantas se desenvolveram em variadas condições de acidez do solo (saturação por bases de $20 \%, 48 \%$ e $67 \%$ ), conforme era esperado e pretendido.

\begin{tabular}{|c|c|c|c|c|c|c|}
\hline \multirow[t]{2}{*}{ Calcário } & \multirow{2}{*}{$\begin{array}{c}\mathrm{pH} \\
\left(\mathrm{CaCl}_{2}\right)\end{array}$} & \multirow[t]{2}{*}{$\mathrm{H}^{+}+\mathrm{Al}^{3+}$} & \multicolumn{3}{|c|}{ Cátions trocáveis } & \multirow[t]{2}{*}{ V } \\
\hline & & & $\mathrm{Ca}^{2+}$ & $\mathrm{Mg}^{2+}$ & $\mathrm{K}^{+}$ & \\
\hline $\mathrm{tha}^{-1}$ & & \multicolumn{4}{|c|}{-------- $\mathrm{mmol}_{\mathrm{c}} \mathrm{dm}^{-3}$} & $\%$ \\
\hline 0 & 4,1 & 63,7 & 7 & 6 & 2,6 & 20 \\
\hline 4 & 4,7 & 35,5 & 18 & 13 & 2,2 & 48 \\
\hline 6 & 5,3 & 27,5 & 33 & 22 & 2,7 & 67 \\
\hline
\end{tabular}

A calagem aumentou significativamente a matéria seca da parte aérea das plantas (Figura 1). Na cultura do amendoim, a calagem pode aumentar o crescimento da parte aérea das plantas, sem causar alteração no desenvolvimento da parte frutífera (Caires \& Rosolem, 1996). Embora a matéria seca de raízes não tenha sido influenciada pela calagem (Figura 1), o aumento do teor de cálcio trocável e da saturação por bases do solo mediante a aplicação de calcário possivelmente aumentou a densidade de comprimento de raízes de amendoim, conforme discutido por Caires \& Rosolem (1998) em trabalho com os cultivares Tatu e Tupã.

A aplicação de calcário proporcionou aumento quadrático no número e na matéria seca de nódulos de amendoim (Figura 2). É importante destacar a dificuldade existente para esse tipo de avaliação na cultura do amendoim, devido à grande quantidade de nódulos com 


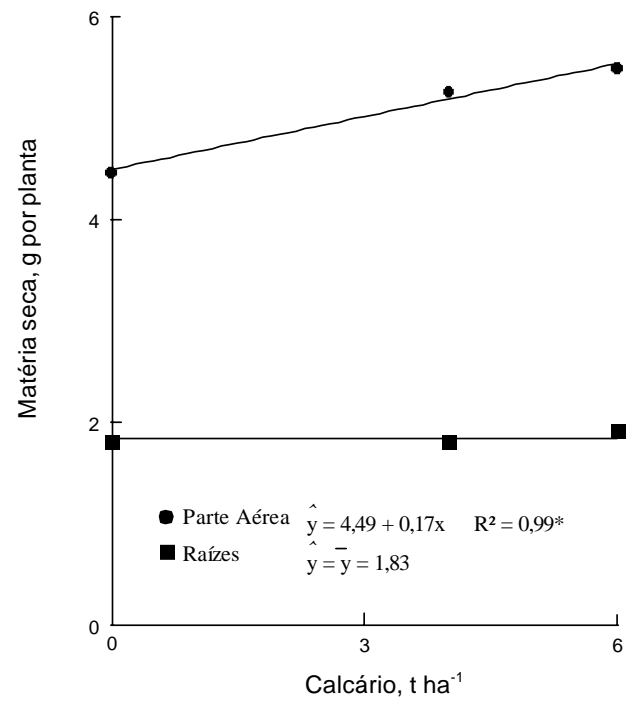

Figura 1 - Matéria seca da parte aérea e de raízes de amendoim, 74 dias após a emergência, em função da calagem. Pontos são médias de 4 tratamentos de sementes e 4 repetições. * Significativo $P<0,05$.
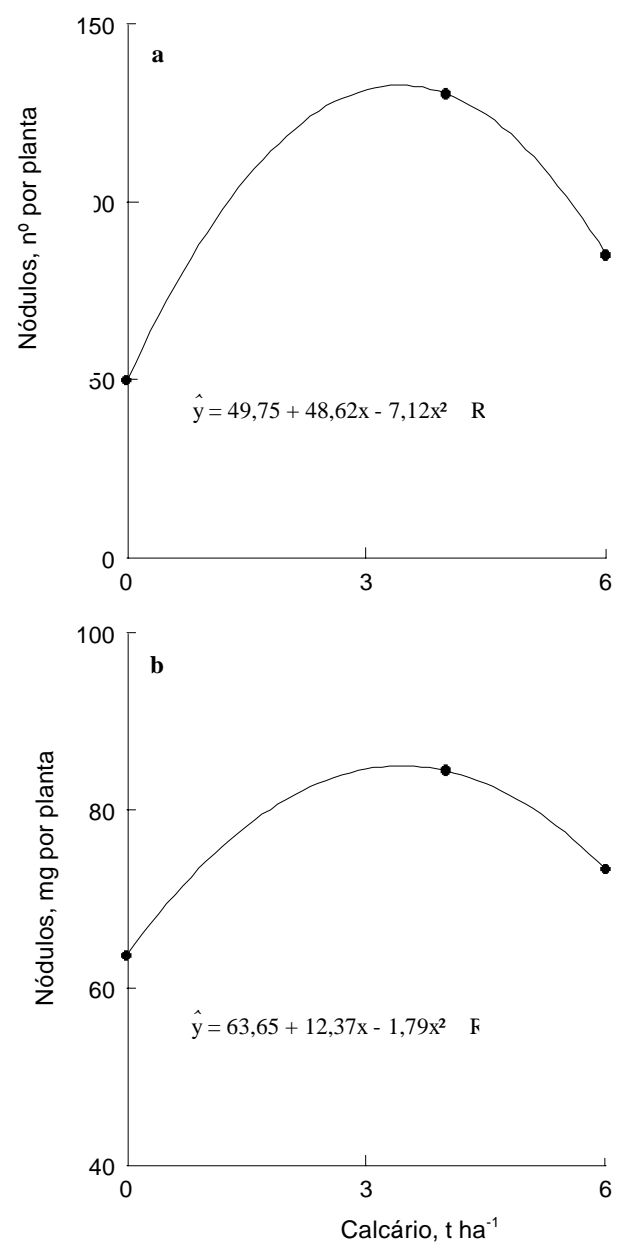

Figura 2 - Quantidade de nódulos de amendoim, em número (a) e massa seca (b) por planta, 74 dias após a emergência, em função da calagem. Pontos são médias de 4 tratamentos de sementes e 4 repetições. pequeno diâmetro. De acordo com as curvas calculadas, a máxima quantidade de nódulos, em número e massa, seria obtida com a dose de $3,4 \mathrm{t} \mathrm{ha}^{-1}$ de calcário, em $\mathrm{pH}$ $\left(\mathrm{CaCl}_{2}, 0,01 \mathrm{~mol} \mathrm{~L}^{-1}\right)$ e saturação por bases próximos de 4,7 e $48 \%$, respectivamente (TABELA 1). Esses valores muito se aproximam dos obtidos para a máxima produção de amendoim dos cultivares Oirã (Caires \& Rosolem, 1993), Tatu e Tupã (Caires \& Rosolem, 1995). Esses resultados confirmam ainda as observações de Blamey \& Chapman (1982), Blamey (1983) e Anandan et al. (1985), segundo as quais a calagem melhora a nodulação das plantas de amendoim.

A melhoria da nodulação das plantas proporcionada pela calagem (Figura 2) resultou em maior absorção de nitrogênio pelo amendoim (Figura 3a). Esse aumento na absorção de nitrogênio pode ser conseqüência da melhoria da nodulação das plantas ocasionada pela redução do alumínio tóxico do solo (Blamey \& Chapman, 1982; Blamey, 1983). Também não se pode desprezar o efeito da calagem na maior mineralização de nitrogênio orgânico do solo em função da elevação do pH (Rosolem et al., 1990). Em solos com baixo valor de $\mathrm{pH}$, a concentração de alumínio trocável pode impedir o crescimento da plantas, mas Nakagawa et al. (1987) concluíram que a toxicidade de manganês é mais importante do que a de alumínio para o cultivar Tatu. Além disso, Caires \& Rosolem (1991) verificaram que o cálcio trocável apresentou maior correlação do que o alumínio trocável com o crescimento de raízes de amendoim. Nota-se, por outro lado, que a absorção de manganês foi sensivelmente reduzida com a calagem (Figura $3 b$ ), certamente em decorrência da redução da solubilidade de manganês no solo pela elevação do $\mathrm{pH}$. Resultados semelhantes foram obtidos por Rosolem \& Caires (1998) com a aplicação de $4 \mathrm{t} \mathrm{ha}^{-1}$ calcário, a qual elevou o $\mathrm{pH}\left(\mathrm{CaCl}_{2} 0,01 \mathrm{~mol} \mathrm{~L}^{-1}\right)$ a 4,8 e a saturação por bases a $48 \%$, eliminando completamente os sintomas de toxicidade de manganês no amendoim.

A análise de correlação entre a quantidade de nódulos, em número e massa, e a absorção de nitrogênio, manganês e cálcio pelas plantas é mostrada na TABELA 2. Nota-se que o número de nódulos foi um parâmetro mais adequado do que a matéria seca de nódulos para avaliação da nodulação do amendoim. O aumento da absorção de nitrogênio (Figura 3a) pela calagem foi ocasionado, pelo menos em parte, pela melhoria da fixação simbiótica do $\mathrm{N}_{2}$ em decorrência da formação de maior número de nódulos na planta, que foi favorecida pela redução da toxicidade de manganês (Figura 3b). Como a absorção de cálcio também correlacionou-se positivamente com o número e não com a matéria seca de nódulos, é possível que o aumento na produção de amendoim pela elevação da relação $\mathrm{Ca} / \mathrm{Mn}$ nas folhas (Rosolem \& Caires, 1998) seja conseqüência do aumento do número de nódulos pela planta, o que melhoraria a fixação biológica do nitrogênio. 

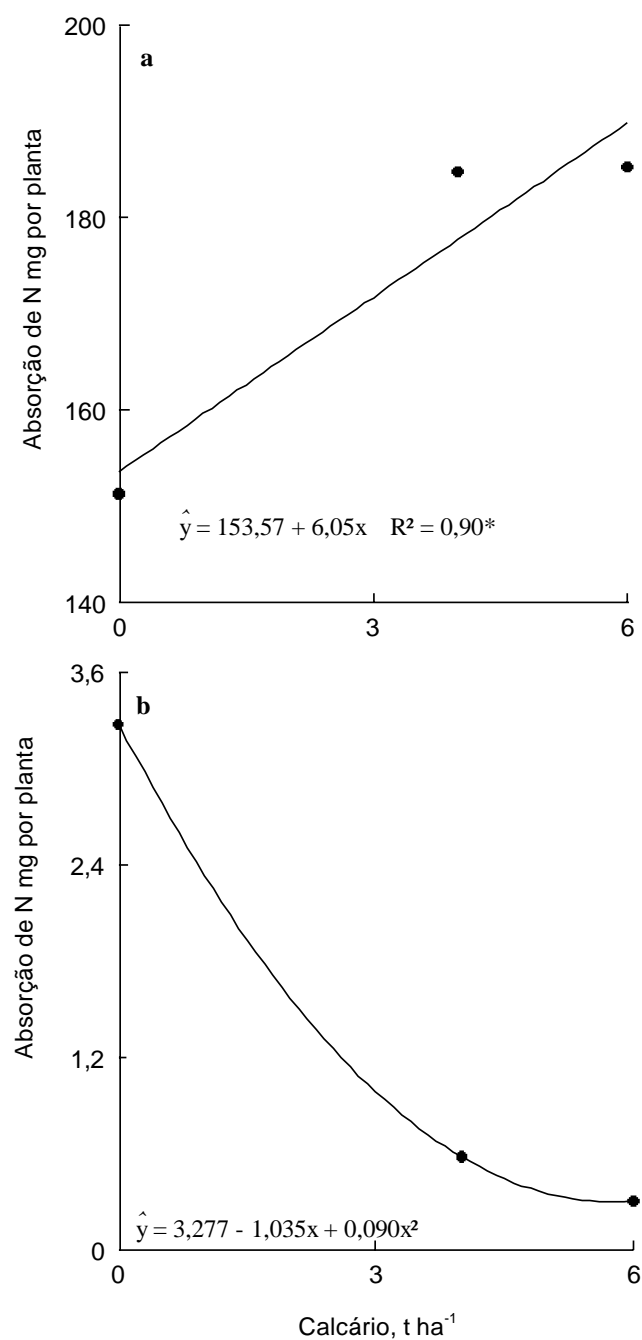

Figura 3 - Absorção de nitrogênio(a) e de manganês (b) pelo amendoim, 74 dias após a emergência, em função da calagem. Pontos são médias de 4 tratamentos de sementes e 4 repetições. * Significativo $\mathrm{P}<0,05$.

TABELA 2 - Coeficientes de correlação entre a quantidade de nódulos de amendoim, em número e massa seca (mg) por planta, e a absorção de nitrogênio, manganês e cálcio (mg por planta).

\begin{tabular}{lccc}
\hline \multirow{2}{*}{ Nó dulos } & \multicolumn{3}{c}{ Absorção } \\
\cline { 2 - 4 } & Nitrogênio & Manganês & Cálcio \\
\hline Número & $0,73^{\star *}$ & $-0,66^{\star}$ & $0,73^{\star *}$ \\
Massa seca & 0,53 & $-0,51$ & 0,53 \\
\hline
\end{tabular}

** Significativo $P<0,01$ * Significativo $P<0,05$

A aplicação de cobalto e molibdênio nas sementes não influenciou significativamente a produção de matéria seca da parte aérea e de raízes. A produção de matéria seca da parte aérea foi de 4,69, 5,22, 4,97 e 5,40 e de raízes $1,65,1,94,1,85$ e 1,90 g planta $^{-1}$, respectivamente para os tratamentos testemunha, Co, Mo e Co + Mo. Caires \& Rosolem (1995) também não observaram influência da aplicação de cobalto e molibdênio na produção de vagens e grãos de amendoim, em solo com alta acidez.
A aplicação de molibdênio aumentou a matéria seca de nódulos, mas não interferiu de forma significativa no número de nódulos (Figura 4). Mesmo assim, a absorção de nitrogênio não foi influenciada significativamente pela aplicação de molibdênio nas sementes, com aumento médio de apenas 12\% (156 e 175 mg por planta de $\mathrm{N}$, respectivamente para os tratamentos testemunha e com Mo). Isto, certamente, ocorreu porque a matéria seca de nódulos não se correlacionou com a absorção de nitrogênio (TABELA 2), mostrando que a redução da toxicidade de manganês pela calagem foi mais importante do que o aumento da disponibilidade de molibdênio para a formação de nódulos e a fixação simbiótica do $\mathrm{N}_{2}$. É possível que em solos ácidos de baixa capacidade de troca catiônica e com menor toxicidade de manganês, a aplicação de molibdênio possa ter melhor efeito sobre a fixação simbiótica do $\mathrm{N}_{2}$ e a absorção de nitrogênio, conforme constatado por Hafner et al. (1992).

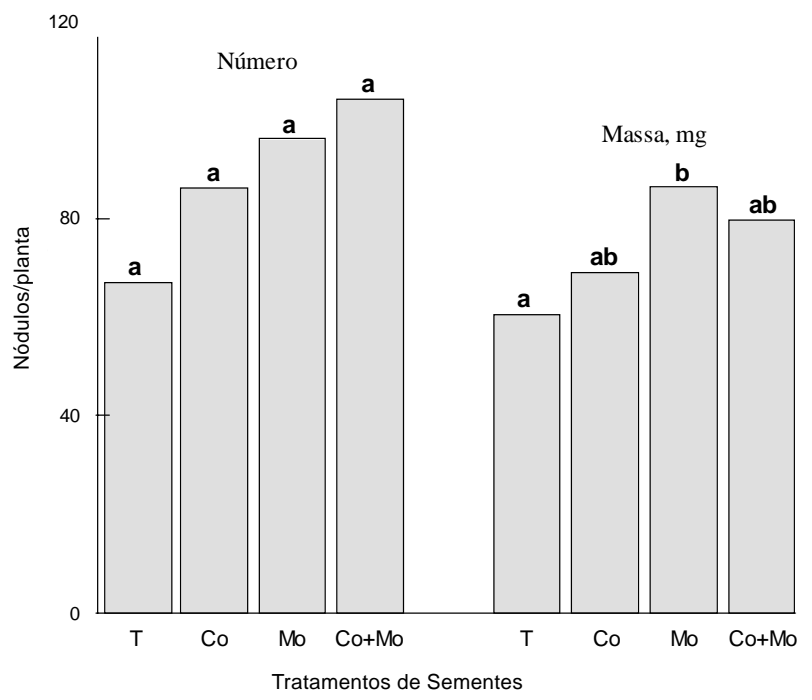

Figura 4 - Efeitos da aplicação de cobalto e molibdênio sobre o número e a massa seca de nódulos de amendoim, 74 dias após a emergência. Pontos são médias de 3 doses de calcário e 4 repetições. Letras iguais não diferem significativamente pelo teste de Tukey a $5 \%$.

Com relação ao cobalto, não foram confirmados os resultados obtidos por Raj (1987), pois não houve melhoria significativa da nodulação (Figura 4) e da absorção de nitrogênio (156 e 178 mg por planta de N, respectivamente para os tratamentos testemunha e com Co) com a sua aplicação. Em outros trabalhos, a aplicação de cobalto também não influenciou significativamente a absorção de nitrogênio (Rosolem \& Caires, 1998), a concentração de clorofila (Caires \& Rosolem, 1999) e a produção de amendoim (Caires \& Rosolem, 1995).

\section{CONCLUSÕES}

- A calagem aumenta a absorção de nitrogênio pelo amendoim, provavelmente por causar melhoria na fixação simbiótica do $\mathrm{N}_{2}$ em decorrência da formação de maior número de nódulos na planta. 
- Apesar do molibdênio causar aumento na matéria seca de nódulos na planta de amendoim, a sua aplicação não influencia a absorção de nitrogênio, mostrando que a redução da toxicidade de manganês pela calagem é mais importante do que o aumento da disponibilidade de molibdênio para a formação de nódulos e a fixação simbiótica do $\mathrm{N}_{2}$.

- A aplicação de cobalto nas sementes não exerce efeito sobre a nodulação e a absorção de nitrogênio pelo amendoim.

\section{REFERÊNCIAS BIBLIOGRÁFICAS}

ANANDAN, K.M.S.; CHANDRASEKARAN, S.; ARUNACHALAN, $G$. Effects of lime on exchangeable aluminum, nodulation on yield of peanut (Arachis hypogaea L.) in an acid Oxisol. Tropical Agriculture, v.62, p.38-40, 1985.

BLAMEY, F.P.C. Acid soil infertility effects on peanut yields and yield components. Communications in Soil Science and Plant Analysis, v.14, p.373-386, 1983.

BLAMEY, F.P.C.; CHAPMAN, J. Soil ameriolation effects on peanut growth, yield and quality. Plant and Soil, v.65, p.319-334, 1982.

CAIRES, E.F.; ROSOLEM, C.A. Root growth of peanut cultivars and soil acidity. In: WRIGHT, R.J.; BALIGAR, V.C.; MURRMANN, R.P. (Ed.) Plant-soil interactions at low pH. Dordrecht: Kluwer, 1991. p.239-243.

CAIRES, E.F.; ROSOLEM, C.A. Calagem em genótipos de amendoim. Revista Brasileira de Ciência do Solo, v.17, p.193-202, 1993.

CAIRES, E.F.; ROSOLEM, C.A. Calagem e aplicação de cobalto e molibdênio na cultura do amendoim. Bragantia, v.54, p.361-370, 1995.

CAIRES, E.F.; ROSOLEM, C.A. Efeitos da calagem sobre o índice de área foliar e a acumulação de matéria seca em genótipos de amendoim. Científica, v.24, p.115-126, 1996.

CAIRES, E.F.; ROSOLEM, C.A. Correção da acidez do solo e desenvolvimento do sistema radicular do amendoim em função da calagem. Bragantia, v.57, p.175-184, 1998.

CAIRES, E.F.; ROSOLEM, C.A. Efeitos da calagem, cobalto e molibdênio sobre a concentração de clorofila nas folhas de amendoim. Revista Brasileira de Ciência do Solo, v.23, p.79-84, 1999.
COLWELL, W.E.; BRADY, N.C. The effect of calcium on certain characteristics of peanut fruit. Journal of the American Society of Agronomy, v.37, p.696-708, 1945.

HAFNER, H.; NDUNGURN, B.J.; BATIONO, A.; MARSCHNER, $H$. Effects of nitrogen, phosphorus and molybdenum application on growth and symbiotic $\mathrm{N}_{2}$ fixation of groundnut in an acid sandy soil in Niger. Fertilizer Research, v.31, p.69-77, 1992.

MALAVOLTA, E.; VITTI, G.C.; OLIVEIRA, S.A. Avaliação do estado nutricional das plantas: princípios e aplicações. 2.ed. Piracicaba: Potafós, 1997. 319p.

NAKAGAWA, J.; VILAS BOAS, R.L.; HELIODORO, B. Toxidez de manganês na cultura do amendoim (Arachis hypogaea L.), cv. Tatu (identificação de um problema). Revista de Agricultura, v.62, p.157-162, 1987.

QUAGGIO, J.A.; DECHEN, A.R.; RAIJ, B. van. Efeitos da aplicação de calcário e gesso sobre a produção de amendoim e lixiviação de bases do solo. Revista Brasileira de Ciência do Solo, v.6, p.186-194, 1982.

RAIJ, B. van; QUAGGIO, J.A. Métodos de análise de solo para fins de fertilidade. Campinas: Instituto Agronômico, 1983. 31p. (Boletim Técnico, 81)

RAJ, A.S. Cobalt nutrition of pigeonpea and peanut in relation to growth and yield. Journal of Plant Nutrition, v.10, p.2137-2145, 1987.

ROSOLEM, C.A.; CAIRES, E.F. Yield and nitrogen uptake of peanuts as affected by lime, cobalt and molybdenum. Journal of Plant Nutrition, v.21, p.827-835, 1998.

ROSOLEM, C.A.; PEREIRA, H.F.M.; BESSA, A.M.; AMARAL, P.G. Nitrogen in soil and cotton growth as affected by liming and $\mathrm{N}$ fertilizer. In: WRIGHT, R.J.; BALIGAR, V.C.; MURRMANN, R.P. (Ed.) Plant-soil interactions at low pH. Dordrecht: Kluwer, 1990. p.321-325.

WALKER, M.E. Calcium requeriments for peanuts. Communications in Soil Science and Plant Analysis, v.6, p.299-313, 1975.

WALKER, M.E.; MULLINIX JUNIOR., B.G.; KEISLING, T.C. Calcium level in the peanut fruiting zone as influenced by gypsum particle size and application rate and time. Communications in Soil Science and Plant Analysis, v.12, p.427-439, 1981.

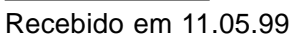

